\title{
PLEOMORPHIC ADENOMA OF THE PAROTID GLAND: REPORT OF A CASE WITH REVIEW OF LITERATURE
}

Jain $\mathbf{S}^{2}$, Hasan $\mathbf{S}^{1}$, Vyas $\mathbf{N}^{2}$, Shah $\mathbf{N}^{2}$, Dalal $\mathbf{S}^{2}$

ABSTRACT

BACKGROUND: Pleomorphic adenomas are benign salivary gland tumors, which predominantly affect the superficial lobe of the parotid gland. The "pleomorphic" nature of the tumor can be explained on the basis of its epithelial and connective tissue origin. The tumor has a female predilection between 30-50 years of age. Slowly progressing asymptomatic swelling is the usual presentation of the tumor. Surgical excision of the tumor mass forms the mainstay of treatment, with utmost care taken to preserve the facial nerve.

CASE DETAILS: This case report aims to throw light on an interesting case of pleomorphic adenoma of the parotid gland in a 50 years old female patient. The patient presented with a slowly progressing asymptomatic swelling on the left side of the face. There is also a special emphasis to a detailed review of literature.

CONCLUSION: Salivary gland neoplasms can occur at any site where salivary tissue is present. Pleomorphic adenoma is the commonest salivary gland tumor characterized by diverse histomorphological features. Early diagnosis and treatment plan entails thorough history taking, clinical examination, coupled with radiographic and histopathological findings.

KEYWORDS: Benign salivary gland tumors, Pleomorphic adenomas, Parotidectomy

DOI: http://dx.doi.org/10.4314/ejhs.v25i2.13

\section{INTRODUCTION}

Pleomorphic adenoma (PA), also known as benign mixed tumor, is the most common salivary tumor, constituting up to two-thirds of all salivary gland neoplasms (1). Mostly, PA is located in the parotid glands (85\%), minor salivary glands $(10 \%)$, and the submandibular glands (5\%) (2). In the majority of cases, tumors originate in the superficial lobe. However, occasional cases may involve the deep lobe of the parotid gland (3) and the parapharyngeal space. Minor salivary gland tumors are frequently encountered on the palate, followed by the lip, cheek, tongue and floor of the mouth (4). PA usually manifest as a slow progressing asymptomatic, parotid gland swelling without facial nerve involvement (5). They are best treated by a wide local excision with good safety margins and follow-up for at least 3-4 years (6).
A 50 years old female patient reported to the Outpatient Department with a chief complaint of slow growing, painless swelling on the left side of face since 5 years. The swelling was initially small in size and had progressively increased with time to attain the present size. Past medical and surgical history was noncontributory. Extra-oral clinical examination revealed a marked facial asymmetry. A well-defined, ovoid, multilobular swelling, $8 \mathrm{x}$ $10 \mathrm{~cm}$ in diameter was seen on the left side of the face. The swelling had a superioinferior extent from left zygomatic arch to about $1 \mathrm{~cm}$ below the lower border of mandible and anteroposterior extent from mid body region to the posterior border of mandible. The left ear lobule was slightly everted. Loss of wrinkling of the skin and engorged veins was also seen (Figure 1).

The swelling was firm in consistency, nontender and warm on palpation. It was fixed to the underlying structures and the overlying skin.

\footnotetext{
${ }^{1}$ Department of Oral Medicine and Radiology, Faculty of Dentistry, Jamia Millia Islamia, New Delhi, India

${ }^{2}$ Department of Oral Surgery, Ahmedabad Dental College, Ahmedabad, Gujrat, India

Corresponding Author: Hasan Shamimul, Email: shamim0571@gmail.com
} 
Facial and eye movements were normal on examination. Intraoral clinical examination was unremarkable. A provisional diagnosis of benign tumor of the left parotid gland was taken into consideration. Pleomorphic adenoma, Warthin's tumor and neuroma of the facial nerve (nerve sheath tumor) were considered as the most probable differential diagnosis. Warthin's tumor is usually seen in elderly males with a history of smoking, does not cause eversion of the ear lobe, located in the lower portion of the parotid (near angle of mandible), and $10-15 \%$ cases show bilateral involvement. Benign tumor of nerve sheath origin in the parotid gland poses difficulty in preoperative diagnosis because of the low frequency of occurrence $(0.2 \%$ to $1.5 \%)$. Also, preoperative diagnosis of a parotid tumor as neuroma seems challenging without accompanying facial nerve dysfunction.

Panoramic radiographic examination did not reveal any abnormality. Magnetic resonance imaging (MRI) revealed a large $(6.1 \mathrm{x} 2.3 \mathrm{x}$ $4.9 \mathrm{~cm})$, well-defined, lobulated, heterogeneous lesion involving the left upper gingiva-buccal sulcus, left retromolar region and bilateral pterygoid muscles posteriorly. The lesion extended superiorly to the infratemporal fossa with infiltration of the infratemporal fat and caused bowing of the posterolateral wall of left maxillary sinus and laterally abutted the masseter muscle. Lesion on $\mathrm{T} 1$ weighted MR image appeared hypointense and appeared hyperintense on T2 weighted MR images (Figure 2).

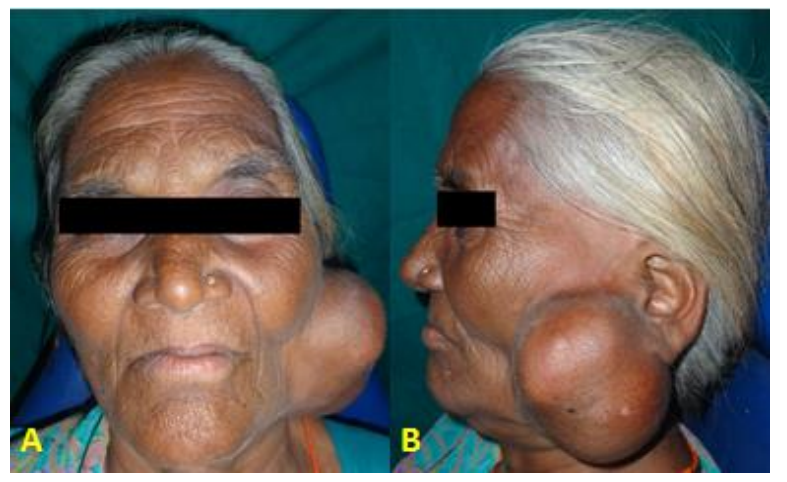

Fig 1: . (A) Frontal view and (B) Lateral view of the face showing left sided facial swelling.

Ultrasonography of the left parotid gland showed a hypoechoic area. Fine needle aspiration cytology (FNAC) was performed under local anesthesia and showed admixed epithelial, myoepithetial and mesenchymal tissue elements.

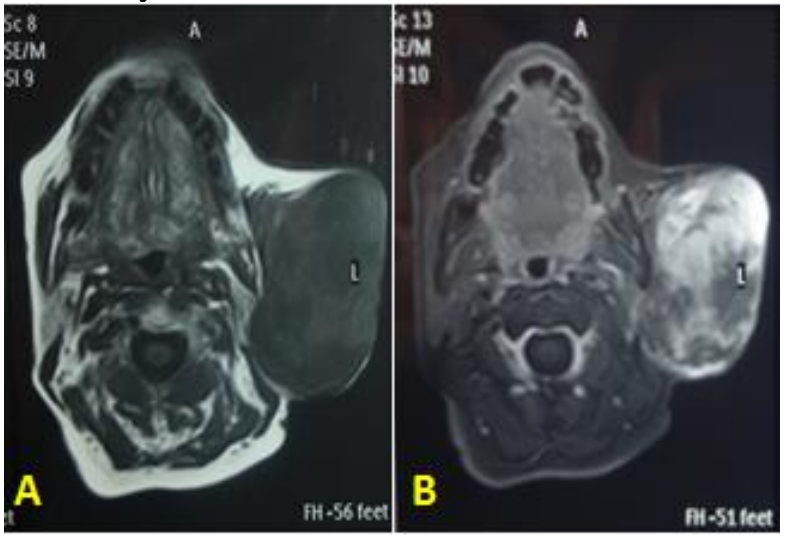

Fig 2: (A) Axial MRI - T1 weighted image showing a hypo intense lesion. (B) Axial MRI T2 weighted image showing a hyper intense lesion.

After obtaining the informed consent of the patient, excision of the superior lobe of the left parotid gland along with the tumor mass was made. A modified Blair incision was given to the left preauricular region; platysma muscle and superficial musculoaponeurotic layer were dissected. The peripheral nerve branches were identified and preserved following a retrograde approach. Nerves were separated from the underlying parotid gland. The tumor was resected after separation from the facial nerve and the masseter muscle (Figure 3)

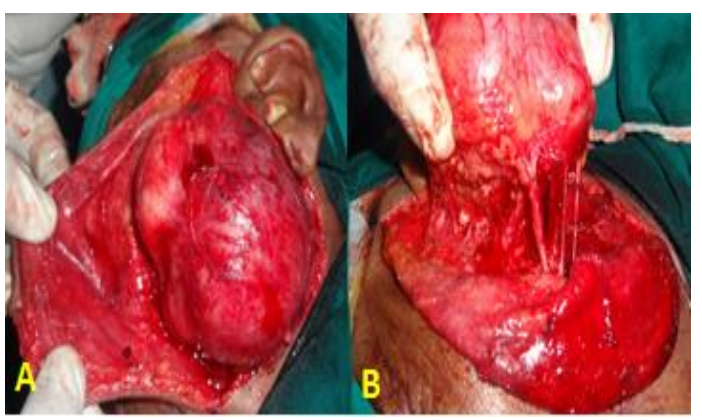

Fig 3: (A) Blunt dissection with the exposed tumor mass. (B) Intraoperative procedure showing the separation of tumor mass from the nerve bundles.

The excised tumor mass was $8 \mathrm{cms}$ x $10 \mathrm{cms} \times$ $12 \mathrm{cms}$ in dimension. The weight of the excised mass was 1.8 kilograms (Figure 4). Histopathology revealed a well capsulated, highly cellular mass with interspersed epithelial cells and myoepithelial cells containing eosinophillic 
cytoplasm. Presence of mucoid material between the tumor cells imparted a myxomatous background. Chondroid and ductal areas along with fat and osteoid were also seen (Figure 5). Pleomorphic adenoma, myoepithelioma and adenoid cystic carcinoma were considered as the probable histologic differential diagnosis. The presence of chondromyxoid foci along with glanduloductal differentiation excluded the histological diagnosis of myoepithelioma. Lack of infiltrative growth pattern and perineural invasion ruled out adenoid cystic carcinoma. The characteristic features of chondromyxoid foci and glanduloductal differentiation confirmed the diagnosis of pleomorphic adenoma of the left parotid gland.

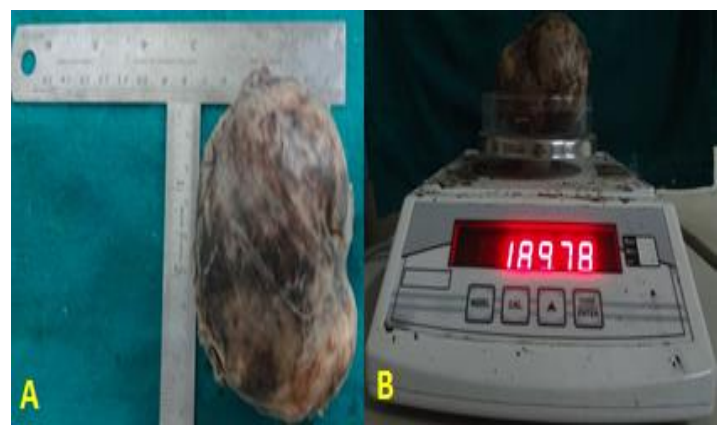

Fig 4: (A) Gross specimen of the resected tumor mass. (B) Tumor mass weighing $1.89 \mathrm{kgs}$.

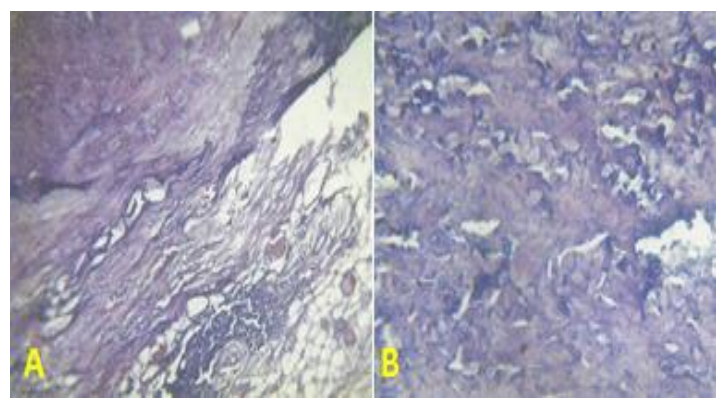

Fig 5: (A) Photomicrograph showing epithelial cells in sheets and cords with chondro myxoid stroma. (10X) (B) Photomicrograph revealing the characteristic features of a pleomorphic adenoma includes islands and strands of epithelium in a myxoid stroma. (40X)

The patient was periodically followed up for 3 years and no recurrences or complications were observed during this period (Figure 6).

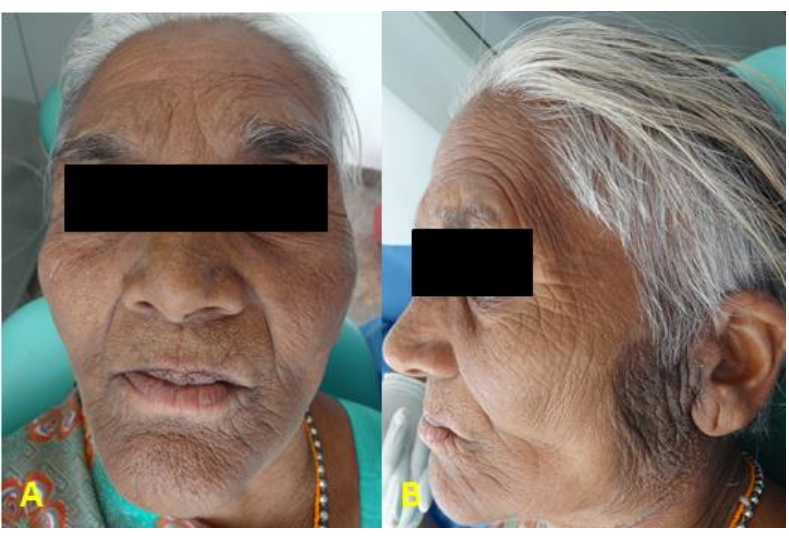

Fig 6: (A) Post- operative facial view. (B) Lateral view showing no recurrence of lesion after followup of 3 years.

\section{DISCUSSION}

World Health Organization (1972) defined PA as a well-defined tumor characterized by its pleomorphic or mixed appearance. There is intermixing of the clearly recognizable epithelial component with mucoid, myxoid and chondroid component (7). Although the lesion presents several histological features due to the different compounds with a myxoid or chondroid matrix, it is generally considered to be a benign neoplasm $(8,9)$.

The exact etiology is obscure although the incidence increases from 15-20 years after exposure to radiation. Few studies have suggested an association of the tumor with simian virus 40 (SV 40) (10).

Pleomorphic adenomas are generally discovered during routine physical examination, as an asymptomatic mass. PA has a glandular origin in the head and neck region and usually manifests as a mobile, slow progressing, asymptomatic firm swelling that does not cause ulceration of the overlying mucosa (11). The majority of these tumors measure 2-6 cm in size when excised (12). However, large tumor may be seen as a single, irregular nodular mass stretching the overlying skin or mucosa (13). The tumor may weigh from several grams to more than 8 kilograms (14). Parotid gland PA is usually seen below the lobule of the ear and overlying the angle of the mandible. Facial nerve weakness is an infrequent sign in parotid tumors although large neglected tumors may present with facial nerve weakness $(15,16)$. Oral retrotonsillar mass/ parapharyngeal space 
tumor may be a presenting sign in cases of deep lobe involvement (17).

Based on clinico-pathological and immunehistochemical features of 60 cases of PA in Brazil, Alves et al. Reported that the tumor occurred commonly between the $3^{\text {rd }}$ and $5^{\text {th }}$ decades of life, and $37 / 60(62 \%)$ of the affected patients were women (18).

Our patient was a 50 years old female who presented with a slowly enlarging, multilobular, asymptomatic swelling on the left side of the face since 5 years. The swelling caused stretching of the overlying skin with visible engorged veins and slight deflection of the left ear lobule. The ocular and facial movements were normal, suggestive of intact facial nerve functions. Grossly, the excised tumor mass measured $8 \times 10 \times 12 \mathrm{~cm}$ in diameter and weighed $1.8 \mathrm{kgs}$. The features in the present case were consistent with the previously published literature.

Imaging modalities such as computed tomography (CT) and Magnetic Resonance Imaging (MRI) are essential aids in diagnosis. MRI is favored on the basis of better soft tissue delineation, detailed tumor margin description and the tumor relationship with the surrounding structures (5).

MRI findings in the present case were suggestive of a large well-defined, heterogeneous lesion, which appeared hypointense on $\mathrm{T} 1$ weighted MR image and hyperintense on T2 weighted MR images. Ultrasound imaging helps to differentiate cystic lesions from solid parotid masses, and is also used for assessment of intracapsular versus extra-capsular tumors. PA's have been identified by ultrasound based on their distinct margins and polycyclic shape (19).

Ultrasonographic findings of the present case showed a hypoechoic area in the left parotid gland. FNAC is a reliable procedure that can guide the surgeon to choose the right surgical approach $(20,21)$. The procedure is usually performed following diagnostic imaging to rule out a vascular lesion although it is not the first choice diagnostic tool (22).

The present case showed a combined pattern of epithelial, myoepithetial and mesenchymal components on FNAC. The histopathology presents varied morphological patterns, showing epithelial and myoepithelial cells with interspersed areas of mesenchymal differentiation. Epithelial cells typically form duct-like structures associated with non-ductal cells presenting varying shapes and forms. Myxoid, cartilaginous, hyaline, or osseous differentiation is appreciated in the stromal component. The stroma is presented as a mixture of gland-like epithelium and mesenchyma-like tissue in varying proportions (13).

As pleomorphic adenoma exhibits a varied histopathologic presentation, it may be confused histopathologically withmyoepithelioma, Adenoid cystic carcinoma, mucoepidermoid carcinoma and basal cell adenoma.

Myoepitheliomas may be considered as a variant of pleomorphic adenoma, but lacking the typical feature of glandulo ductal differentiation (23). Another characteristic feature of myothelioma is the absence of chondromyxoid or chondroid foci (24). Chondromyxoid foci and glanduloductal differentiations are the hallmark feature in pleomorphic adenomas.

Adenoid cystic carcinoma shows epithelial and myoepithelial differentiation in three forms: Cribriform, Tubular, and Solid (25). However, the infiltrative growth pattern and tendency for perineural invasion are the salient features of adenoid cystic carcinoma.

The intermediary cells in mucoepidermoid carcinoma show similarity to the basal/ myoepithelial cells of pleomorphic adenoma. Although the intermediary cells have the potential to produce the extracellular material, they lack the ability to create the myxochondroid stroma. Also, squamous differentiation (when present in pleomorphic adenoma) is generally well developed and may show keratinisation. This feature is less evident in carcinoma (26).

Basal cell adenoma is a subtype of pleomorphic adenoma, and was previously termed as monomorphic adenoma. The tumor can be histologically differentiated from pleomorphic adenoma by the absence of chondromyxoid stroma and the presence of a uniform basaloid epithelial pattern.

Histopathological features in the current case showed salient features of pleomorphic adenoma. A well-capsulated cellular mass of sheets and islands of epithelial cells and rounded myoepithelial cells, along with myxomatous background and ductal architecture, was clearly evident. 
Aggressiveness and extent of the tumor mass and its relation with the facial nerve form the important criteria which dictate the choice of treatment of pleomorphic adenoma of the parotid gland. Enucleation, enucleoresection and superficial or total parotidectomy with preservation of the facial nerve formed the mainstay of surgical treatment (27).

In the present case, superior lobe of the left parotid gland with the tumor mass was excised with utmost care to preserve the facial nerve branches. Pleomorphic adenomas need to be managed diligently as they have a tendency for recurrence and malignant transformation. Rupture of the capsule and subsequent tumor spillage during excision are attributable risk factors for recurrence. Up to $10 \%$ cases show malignant transformation and features predictive of malignant change include advancing age, massive tumor size, a long duration of the mass, occurrence in submandibular salivary gland, and hyalinized connective tissue (28).

The patient in the current case was thoroughly followed up for a period of 3 years and no signs of recurrences were observed during the follow up.

\section{REFERENCES}

1. Califano J, Eisele DW. Benign salivary gland neoplasms. Otolaryngol Clin North Am, 1999; 32:861-73.

2. Luna MA. Salivary glands. In: Pilch BZ, editor. Head and neck surgical pathology. Philadelphia: Lippincott Williams \& Wilkins; 2001: p. 284-349.

3. Morita N, Miyata K, Sakamoto T, Wada T. Pleomorphic adenoma in the parapharyngeal space: report of three cases. J Oral Maxillofac Surg, 1995; 53: 605-610.

4. Vicente OP, Marques NA, Aytes LB, Escoda CG. Minor salivary gland tumors: a clinicopathological study of 18 cases. Med Oral Patol Oral Cir Bucal, 2008; 13(9): 582588.

5. Sergi B, Limongelli A, Scarano E, Fetoni AR, Paludetti G. Giant deep lobe parotid gland pleomorphic adenoma involving the parapharyngeal space. Report of three cases and review of the diagnostic and therapeutic approaches. Acta Otorhinolaryngol Ital, 2008; 28:261-265.
6. Aggarwal A, Singh R, Sheikh S, Pallagatti S, Singla I. Pleomorphic adenoma of minor salivary gland: A case report. RSBO Revista Sul-Brasileira de Odontologia, 2012; 9:97101.

7. Traiger J, Rosen MB. Mixed tumor of the cheek; report of a case. Oral Surg Oral Med Oral Pathol, 1965; 19:711-714.

8. Berdal P, Hall JG. Parapharyngeal growth of parotid tumours. Acta Otolaryngol Suppl, 1969; 263:164-6.

9. Carr RJ, Bowerman JE. A review of tumors of the deep lobe of the parotid salivary gland. $\mathrm{Br}$ J Oral Maxillofac Surg, 1986; 24:155-68.

10. Martinelli M, Martini F, Rinaldi E, Caramanico L, Magri E, Grandi E, et al. Simian virus 40 sequences and expression of the viral large $\mathrm{T}$ antigen oncoprotein in human pleomorphic adenomas of parotid glands. Am J Pathol, 2002; 161(4): 1127-1133.

11. Dalati T, Hussein MR. Juvenile pleomorphic adenoma of the cheek: a case report and review of literature. Diagnostic Pathology, 2009; 4(32): 1-5.

12. Beunting JE, Smith TL, Holmes DK. Giant pleomorphic adenoma of the parotid gland: case report and review of the literature. Ear Nose Throat, J 1998; 77 (8): 643, 637638,640 .

13. Ellis GL, Auclair PL. Tumors of the Salivary Glands (Atlas of Tumor Pathology). 3rd series. Fascicle 17. Washington, DC: Armed Forces of Institute of Pathology; 1996.

14. Guerriere CN, Goff JJ, Cummings GH, Auber AE. An unusually large, solid tumor of the parotid gland. Ann Plast Surg, 1999; 43 (5): 529-532.

15. Silva SJ, Costa GT, Filho ACB, Faria PR, Loyola AM. Metachronous bilateral pleomorphic adenoma of the parotid gland. Oral surgery, Oral Medicine, Oral Pathology, Oral Radiology, and Endodontology, 2006; 101(3):333-338.

16. Jr Takahama A, Perez DEC, Magrin J, Almeida OP, Kowalski LP. Giant pleomorphic adenoma of the parotid gland. Med Oral Patol Oral Cir Bucal, 2008; 13(1): 58-60.

17. Hakeem AH, Hazarika B, Pradhan SA, Kannan R. Primary pleomorphic adenoma of minor salivary gland in the parapharyngeal 
space. World Journal of Surgical Oncology, 2009; 7(85): 1-4

18. Alves FA, Perez DE, Almeida OP, Lopes MA, Kowalski LP. Pleomorphic adenoma of the submandibular gland: Clinicopathological and immunohistochemical features of 60 cases in Brazil. Arch Otolaryngol Head Neck Surg, 2002; 128:1400-1403.

19. E.J. Bialek, W. Jakubowski, G. Karpinska. Role of ultrasonography in diagnosis and differentiation of pleomorphic adenomas. Arch Otolaryngol. Head Neck Surg, 2003; 129: 929-933.

20. Contucci AM, Corina L, Sergi B, Fadda G, Paludetti G. Correlation between fine needle aspiration biopsy and histologic findings in parotid masses. Personal experience. Acta Otorhinolaryngol Ital, 2003; 23: 314-318.

21. Sergi B, Contucci AM, Corina L, Paluteddi G. Value of fine needle aspiration cytology of parotid gland masses. Laryngoscope, 2004; 114: 789.

22. Yousem DM, Sack MJ, Scanlan KA. Biopsy of parapharyngeal space lesions. Radiology, 1994; 193: 619-622.
23. Dardick I. Myoepithelioma: definitions and diagnostic criteria. Ultrastruct Pathol, 1995 Sep-Oct;19(5):335-45. .

24. Sciubba JJ, Brannon RB. Myoepithelioma of salivary glands: report of 23 cases. Cancer, 1982;49(3):562-72.

25. Szanto PA, Luna MA, Tortoledo ME, White RA. Histologic grading of adenoid cystic carcinoma of the salivary glands. Cancer, 1984;54:1062-69.

26. Lewis JE, Olsen KD, Sebo TJ. Carcinoma ex pleomorphic adenoma: pathologic analysis of 73 cases. Hum Pathol, 2001; 32: 596-604.

27. Mehle ME, Krause DH, Wood BG, Benninger SM, Eliachar I, Levine HL, et al. Facial nerve morbidity following parotid surgery for benign disease. The Cleveland Clinic Foundation Experience. Laryngoscope, 1993; 103: 386-388.

28. R.J. Zarbo. "Salivary gland neoplasia: a review for the practicing pathologist". Modern Pathology, 2002; 15 (3): 298-323. 